\title{
Efficient Near-Infrared In Vivo Imaging of Amyoid- $\beta$ Deposits in Alzheimer's Disease Mouse Models
}

\author{
Anke Schmidt ${ }^{\mathrm{a}, \mathrm{c}, 1}$ and Jens Pahnke $\mathrm{e}^{\mathrm{a}, \mathrm{b}, \mathrm{c}, \mathrm{d}, \mathrm{e}, \text {,* }}$ \\ ${ }^{a}$ German Center for Neurodegenerative Diseases (DZNE) Rostock, Rostock, Germany \\ ${ }^{\mathrm{b}}$ German Center for Neurodegenerative Diseases (DZNE) Magdeburg, Magdeburg, Germany \\ ${ }^{\mathrm{c}}$ Neurodegeneration Research Laboratory (NRL), Department of Neurology, University of Rostock, \\ Rostock, Germany \\ ${ }^{\mathrm{d}}$ Neurodegeneration Research Laboratory (NRL), Department of Neurology, University of Magdeburg, \\ Magdeburg, Germany \\ ${ }^{\mathrm{e}}$ Leibniz Institute for Neurobiology (LIN), Magdeburg, Germany
}

Handling Associate Editor: Eric Westman

Accepted 25 February 2012

\begin{abstract}
The development of early diagnostic and prognostic tools for the visualization of amyloid- $\beta$ (A $\beta$ ) deposits is one important focus of current imaging research. In patients with Alzheimer's disease (AD), non-invasive and efficient detection of soluble and aggregated $A \beta$ is important to determine the immediate success of intervention trails. The novel near infraredfluorescence (NIRF) probe THK-265 efficiently penetrates the blood-brain barrier and has a strong and efficient binding to cerebral A $\beta$. Ex vivo microscopy of i) THK-265-labeling of plaques in paraffin-embedded tissue and ii) cerebral cryo-sections after intravenous injection of THK-265 confirmed a systematic increase of the NIRF signal corresponding to A $\beta$ plaque number and size during disease progression. Furthermore, we investigated different stages of plaque formation in amyloid- $\beta$ protein precursor transgenic mice in vivo after intravenous application of THK-265 to evaluate different aggregation levels with NIRF signals. The intensity of the NIRF signal correlated well with the plaque burden, indicating its utility for direct monitoring of A $\beta$ aggregation progression. In summary, our results support the use of the NIRF probe THK-265 for the diagnosis and direct visualization of amyloid deposits and open the possibility for efficient, pre-symptomatic monitoring of A $\beta$ deposition in the aging brain.
\end{abstract}

Keywords: Alzheimer's disease, amyloid- $\beta$, amyloid imaging, in vivo imaging, near-infrared

\section{INTRODUCTION}

In Alzheimer's disease (AD), abnormal, pathological processing and transport of amyloid- $\beta(\mathrm{A} \beta)$ peptides initially lead to clinically minor cognitive

\footnotetext{
${ }^{1}$ Present address: INP Greifswald/ZIK plasmatis, Greifswald, Germany.

*Correspondence to: Jens Pahnke, University of Magdeburg, Leipziger Str. 44, House 15, 39120 Magdeburg, Germany. Tel.: +49 39167 24514; E-mail: jens.pahnke@gmail.com.
}

alterations and morphologically to the formation of $\mathrm{A} \beta$ plaques and tangles with progressive neurodegeneration and overt dementia [1]. To date, available treatment strategies are of low efficacy and only promise limited help for a few months [2, 3]. Furthermore, a reliable diagnosis of $\mathrm{AD}$ during the early stages of cognitive impairment is not yet available, but is currently the subject of considerable research. Some authors have reported that measurement of both phospho-tau (181P) and $\mathrm{A} \beta_{\mathrm{X}-42}$ can enhance 
diagnostic precision during stages of mild cognitive impairment [4-6].

A $\beta$ peptides are the main constituents of cerebral amyloid plaques. They are the products of the proteolytic cleavage and pathological processing of the amyloid- $\beta$ protein precursor (A $\beta P P)$ and may vary in total length from 38 to 43 amino acids, with $A \beta_{42}$ being more toxic then C-terminally shorter moieties [7]. Toxic aggregation products of $A \beta$ such as oligomers, fibrils, and finally, senile plaques differentially contribute to the cognitive decline in patients $[8,9]$. Recent studies using A $\beta P P$-transgenic mice indicate that small, soluble oligomeric, non-fibrillar, or proto-fibrillar assemblies of $\mathrm{A} \beta$ exhibit the most toxic effects on synaptic connections and neuronal integrity $[10,11]$. Growing evidence indicates that $A \beta$ oligomers may be even more critical than amyloid plaques for the development of AD-related neuronal dysfunction and memory deficits [8, 12], although there is also evidence for a direct pathogenic role of plaques and plaque-associated neuritic dystrophy $[9$, $13,14]$. The accumulation of $A \beta$ deposits leads to neuron loss along with cerebral atrophy and evokes cognitive impairment, a decline of mental faculties, dementia and finally death [15]. The successful early detection of $A \beta$ pathology in patients could enable the definitive preclinical diagnosis of $\mathrm{AD}$, and facilitate quantitative evaluation of the efficacy of anti-A $\beta$ therapeutics.

To track disease progression and to visualize $A \beta$ deposits, the development and application of more efficient, cost-effective, non-invasive detection techniques are essential. Therefore, one focus of research relies on novel optical methods of near infrared fluorescence (NIRF) imaging agents that show high and specific affinity to amyloid deposits in the brain. Particularly useful are small NIRF probes with emission signals that provide a high signal-to-background ratio in the wavelength-range from 700 to $900 \mathrm{~nm}$ [16]. In this context, fluorescence spectroscopy is the most applied method for visualization of amyloid self-assembly [17]. Currently, a number of molecular fluorescent probes for the detection of amyloid self-assembly and plaques are available [18]: Congo red, Thioflavin S/T, fluorescein, and de novo-synthesized probes such as NIAD-4 [19]. Novel luminescent-conjugated polythiophenes (LCPs) cross the blood-brain barrier effectively and stain pre-fibrillar $A \beta$ assemblies and $A \beta$ deposits in the brain $[14,20]$. More importantly, one member of the LCP family has shown distinct spectral signature shifts that correspond to the toxic, pathological $\mathrm{A} \beta$ moieties. Optimal fluorophores, imaging param- eters, and specific features for NIRF imaging of $A \beta$ were recently described by Raymond and colleagues [21]. These workers simulated targeted probe emissions values for $A \beta$ in the range between $630-800 \mathrm{~nm}$ and tested idealized fluorophores in transgenic mouse models. They found that fluorophores with an emission $>800 \mathrm{~nm}$ show better $\mathrm{S} / \mathrm{N}$ ratios and are more sensitive to changes in cerebral $A \beta$ burden during disease progression. The best A $\beta$ NIRF probe tested was the oxazine-derived A $\beta$-binding dye AOI987. In initial studies, the AOI987 (with absorption and emission peaks at 650 and $750 \mathrm{~nm}$ ) was used to distinguish aged, A $\beta P P$-transgenic mice from wild type mice [22]. In A $\beta P P 23$ transgenic mice aged 9 months and older, AOI987 proved to be an efficient probe to monitor disease progression and plaque load in brain. Moreover, the curcumin-derivatized NIRF probe CRANAD-2 was also used as a contrast agent to track $A \beta$ and was used to monitor disease progression [23].

NIRF probes not only target $A \beta$ deposits in $A D$, but also may be suitable for the assessment of other protein aggregates in neurodegenerative diseases. In this regard, another neuropathological hallmark of $\mathrm{AD}$ is the formation of neurofibrillary tangles with intracellular tau aggregates in multiple regions of the brain. ${ }^{18}$ F-THK523 was identified as a novel in vivo tau-imaging ligand for $\mathrm{AD}$ [24]. Binding studies demonstrated that ${ }^{18}$ F-THK523 binds with high affinity and selectivity to tau but not to $\mathrm{A} \beta$ plaques. Also, boron-dipyrromethene (BODIPY)based $\mathrm{Zn}^{++}$-complexes have shown high affinity for hyperphosphorylated proteins and were used to visualize aggregated tau in AD [25]. As an additional probe for hyperphosphorylated tau, Thiazine Red was used as an accurate diagnostic tool for the rapid postmortem diagnosis of AD neuropathology [26].

As an alternative to conventional techniques, the new NIRF probe THK-265 was suggested for detection of cerebral $A \beta$ deposits in A $\beta P P-t r a n s g e n i c$ mice, and may serve as a good candidate for nearinfrared imaging [27]. Fluorescent properties such as emission wavelength greater than $650 \mathrm{~nm}$ showed high quantum yield and molar absorption coefficients, together with high binding affinity to $A \beta$ fibrils $\left(\mathrm{K}_{\mathrm{d}}=97 \mathrm{nM}\right)$.

Here, we describe the development of a systematic procedure that allowed us to visualize $A \beta$ in $A \beta P P$ transgenic mice at different disease stages. Using A $\beta P P$-transgenic mice that develop $A \beta$ deposits as early as 50 days, we performed a longitudinal study starting at different time-points of $A \beta$ pathology: 
75,100 , and $>200$ days. Our goal was to evaluate the methodological requirements and limitations of a near-infrared imaging approach to cerebral $\mathrm{A} \beta$ accumulation using THK-265.

\section{MATERIAL AND METHODS}

\section{Reagents}

THK-265 was obtained from Organica (Wolfen, Germany). The full name of the NIRF compound THK-265 is: 5-(2E,4E)-5-(6-hydroxy-4-oxo-2-thioxo1,2,3,4-tetrahydroxy-5-pyrimidinyl)-2,4pentadienylidene-2-thioxodihydro-4,6 $(1 \mathrm{H}, 5 \mathrm{H})$ pyrimidinedione.

\section{A $\beta P P$-transgenic mouse model of cerebral $\beta$-amyloidosis}

A double mutation transgenic mouse strain on the $\mathrm{C} 57 \mathrm{Bl} / 6$ background was used as an animal model of $\beta$-amyloidosis mimicking AD. This mouse model expresses mutated human A $\beta P P$ swe and mutated human presenilin 1 (L166P) in the $\mathrm{C} 57 \mathrm{Bl} / 6$ genomic background and starts to develop early $\mathrm{A} \beta$ plaques at 6 7 weeks of age [28, 29]. Furthermore, we used FVB/N (white fur), and mixed (B6/129S7, brown fur) genomic backgrounds to test for interference of the fur color with the infrared measurements. Mice were housed under controlled conditions with free access to food and water. For NIRF imaging, mice were anesthetized using rompun/ketanest $(2.5 \%$ and $7.5 \%$, respectively, in $0.9 \% \mathrm{NaCl}$, ZAP Rostock) over $90 \mathrm{~min}$. All consecutive analyses were done after intravenous (i.v.) administration of THK-265 at 75, 100, and 200 days into the tail vein of male and female mice $(n \geq 5)$. Two controls were injected intracerebrally (i.c.) with THK-265 at coordinates relative to bregma, AP: +1 ; L: +2; IB: -2). Age-matched wild-type mice without plaque formation were used as control subjects ( $n \geq 5$, male/female). For comparison of the effectiveness of delivery route, two mice were additionally injected intraperitoneally (i.p.). Plaque imaging was also performed in aged mice (>200 d) for comparison of changes in signal intensity with increased age $(n=5)$.

\section{Determination of cerebral THK-265 uptake by NIRF scanning}

For all in vivo experiments, THK-265 was dissolved in DMSO and further diluted in $0.1 \mathrm{M}$ phosphate-buffered saline (PBS, pH7) supplemented with $0.02 \mathrm{~mol} / \mathrm{l} \mathrm{HCl}$ to the end concentration of maximal $10 \%$ DMSO. For non-invasive imaging of THK-265 in living mice, fluorescence images were taken using an Odyssey ${ }^{\circledR}$ Infrared Imaging System (OIIS, LI-COR Biosciences) equipped with a filter set at $665 \pm 22.5 \mathrm{~nm}$ excitation and $725 \pm 25 \mathrm{~nm}$ emissions. After intravenous administration of THK-265, anesthetized mice were scanned at $700 \mathrm{~nm}$ at different time points $(10,20,30,60$, and $90 \mathrm{~min})$.

\section{Quantitative image analyses}

Scans of whole animals and organs were analyzed using the Odyssey ${ }^{\circledR}$ imaging software (version 3.0). Signal intensities were determined relative to the initial measurements at $30 \mathrm{~min}$ after THK-265 administration. Scan settings were medium or high image quality, 169 or $84 \mu \mathrm{m}$ resolution, intensity $1.0-5.0$ for the 700-channel, with zero z-offset. For quantification, the NIRF signal was analyzed as the average of the $700 \mathrm{~nm}$-channel integrated intensities from $n \geq 5$ mice normalized to the background and correlated to agematched controls. Results are expressed as arbitrary units (means \pm standard errors of the mean).

\section{Quantification of A $\beta$ plaque deposition}

Immunohistochemistry was done as previously described [29-32]. Briefly, formalin-fixed brains were embedded in paraffin and $4 \mu \mathrm{m}$-thick sections were cut. After deparaffinization, the sections were processed using the BOND-MAX ${ }^{\mathrm{TM}}$ autostainer (Leica Microsystems $\mathrm{GmbH} / \mathrm{Menarini}$ ). Immunostaining was initiated after blocking endogenous peroxidase ( $5 \mathrm{~min}$ ) and epitope retrieval for $5 \mathrm{~min}$ with $70 \%$ formic acid. The primary antibody (clone $6 \mathrm{~F} / 3 \mathrm{D}$, anti-human, epitope A $\beta 8-17$, dilution $1: 200$, Dako) was incubated routinely for $30 \mathrm{~min}$ at room temperature. The primary antibody was detected with the BOND-MAX ${ }^{\mathrm{TM}}$ Bond Polymer Refine Detection Kit and standard protocol DAB R30. Slides were fully digitized with a resolution of $230 \mathrm{~nm}$ using the MIRAX ${ }^{\circledR}$ automated slide scanner, and then semi-automatically analyzed using the AxioVision software package (Zeiss MicroImaging $\mathrm{GmbH}$ ).

Additionally, adjacent sections of the brains were prepared in ethanol/xylene and incubated with THK$265(100 \mu \mathrm{M})$ for $10 \mathrm{~min}$. After brief washes in water and PBS, the slides were examined using the OIIS (LICOR Biosciences) and a laser-scanning microscope (LSM700, Zeiss MicroImaging GmbH). 
Ex vivo analysis and in vitro co-labeling of plaques in aged A $\beta P P$-transgenic mice

Immediately after i.v. application of THK-265 and in vivo NIRF scanning, mice were killed, and brains were removed, cryo-protected with (TissueTek OCT compound, Sakura), and frozen sections were cut at $16 \mu \mathrm{m}$ thickness. Immunofluorescence staining of plaques was performed using a primary $\mathrm{A} \beta$-specific antibody (clone 6E10, anti-human, epitope $A \beta_{3-8}, 1: 500$, Covance) and an anti-mouse Cy3 antibody (1:500, goat-anti-mouse, Dianova) for detection. THK-265 and 6E10 co-staining of $\mathrm{A} \beta$ plaques was detected simultaneously using an automated brightfield and fluorescence MiraxMidi slide scanner (Zeiss MicroImaging $\mathrm{GmbH}$ ). Images were also acquired using an inverted microscope (AxioVert Zeiss MicroImaging $\mathrm{GmbH}$ ) equipped with a Cy5 filter set $(665 \pm 22.5 \mathrm{~nm}$ excitation and $725 \pm 25 \mathrm{~nm}$ emission), and a laser scanning microscope (LSM700, Zeiss MicroImaging $\mathrm{GmbH}$ ).

\section{Toxicity and statistical analysis}

All procedures were performed in accordance with animal protocols according to the German animal protection law and approved by the local authorities "Landesamt für Landwirtschaft, Lebensmittelsicherheit und Fischereiwesen Mecklenburg-Vorpommern" (LALLF M-V), Thierfelder Str, 18057 Rostock, Germany. The control group was injected with PBS, whereas the treated group was injected with different concentrations of THK-265 $(0.1,1$, and $10 \mathrm{mg} / \mathrm{kg}$ of body weight). Quantification results are presented as means \pm standard errors of the mean (SEM). Statistical significance analysis was performed using Student's $t$-test with the significance level set at $p<0.05$, twotailed.

\section{RESULTS}

\section{Parameter determination for in vivo NIRF imaging}

To use the fluorescence characteristics of THK265 for the non-invasive detection and real-time monitoring of $\mathrm{A} \beta$ deposition, we developed a procedure that allows the in vivo assessment at different stages of $\beta$-amyloidosis in mice (Fig. 1A). In this regard, we established parameters and conditions for infrared-fluorescence imaging using the OIIS (LICOR Biosciences). The system is equipped with an excitation laser diode at $665 \pm 22.5 \mathrm{~nm}$ and emission detection array at $725 \pm 25 \mathrm{~nm}$.

Starting with control mice on the FVB/N (white fur), C57B1/6 (B6, black fur), and mixed (B6/129S7, brown fur) genomic backgrounds, we detected sufficient signal-to-noise ratios only in B6 mice with a good baseline resolution (Fig. 1B left). The brown and the white fur of the B6/129S7 and FVB/N stains, respectively, resulted in a reflection and refraction of the laser light, generating a high background signal and low $\mathrm{S} / \mathrm{N}$ ratio. Figure 1C illustrates the dorsal position of imaged mice.

To determine the optimal route of THK-265 administration, we tested intravenous, intraperitoneal, and intracerebral applications, each showing a distinctive staining pattern: after intracerebral injection into cortex, a restricted fluorescence signal was obtained (Fig. 1DI), in contrast to intravenous administration with a broad signal in the blood vessels of brain (Fig. 1DII). No near-infrared signal was obtained after intra-peritoneal administration (Fig. 1DIII) even at higher resolution and signal intensity (bottom panels).

\section{Histological analyses of murine brain sections after ex vivo THK-265 incubation}

To confirm that changes in expression intensity were mediated by different quantities of $A \beta$, we performed ex vivo labeling of $\mathrm{A} \beta$ plaques. Co-staining of plaques was done by immunohistochemistry in paraffin-embedded brain slices for control (0), early (I, $75 \mathrm{~d}$ ), middle (II, $100 \mathrm{~d}$ ), and late stages (>200 d, III) of $\mathrm{A} \beta$ deposition using antibody $6 \mathrm{~F} / 3 \mathrm{D}$ (Fig. 2A). To analyze features of plaque staining at different stages of $A \beta$ pathology, appropriate quantitative evaluation methods for stained slides were used. Plaque amount was quantified using $230 \mathrm{~nm}$-high-resolution analysis software after scanning of the $4 \mu \mathrm{m}$ sections by an automated brightfield Mirax slide scanner (Zeiss Microsystems $\mathrm{GmbH}$ ) as previously described [32]. As expected, the first deposits of $A \beta$ appeared after 50 days as isolated small plaques (Fig. 2A0). The number and size of the amyloid plaques increased with animal age; furthermore, the $A \beta$ aggregates spread from cortex, eventually to include the entire brainstem (Fig. 2AI-III). To establish the relationship between $\mathrm{A} \beta$ plaques and plaque-associated THK-265 staining, adjacent sections of hemispheres were prepared in ethanol/xylene, and incubated for $10 \mathrm{~min}$ with THK265. Using OIIS (LI-COR Biosciences) we performed whole brain slice imaging to visualize the NIR fluorescence signal (red plaque core) of $A \beta$ deposition 


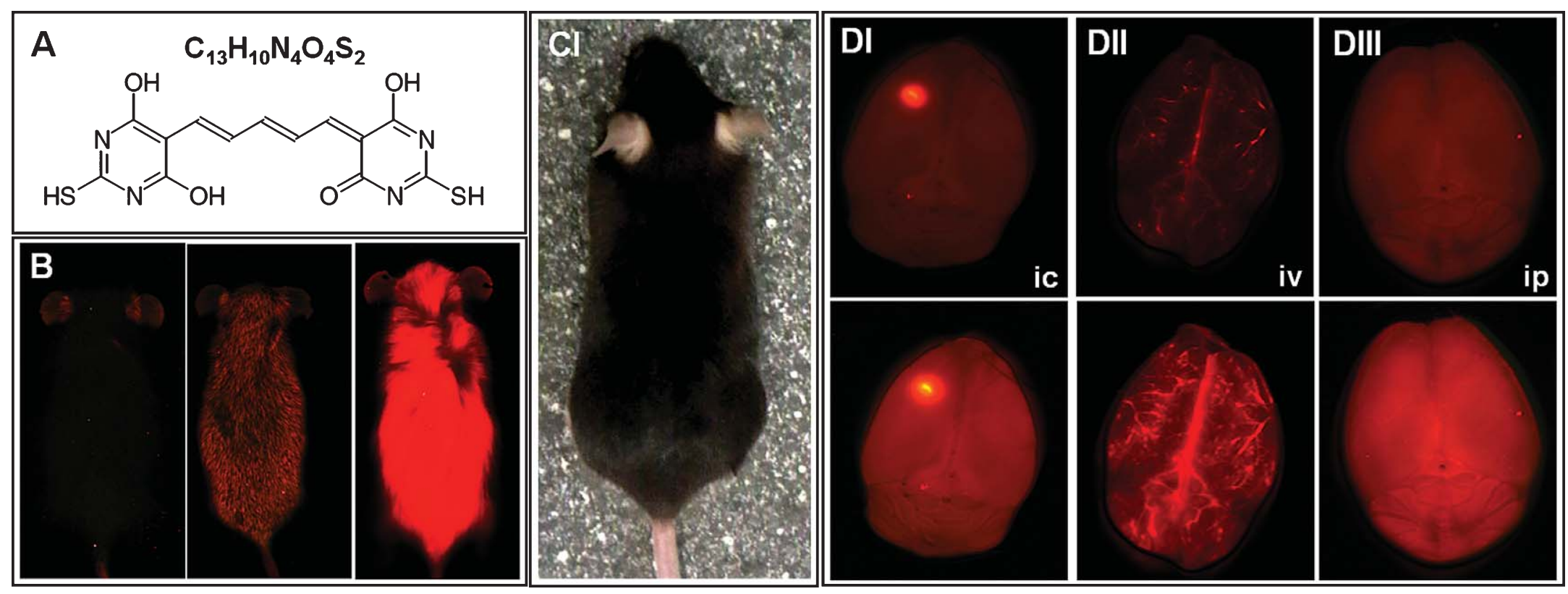

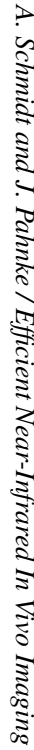

Fig. 1. Establishment of THK-265 staining. A) Chemical structure of near-infrared fluorescence (NIRF) probe THK-265. B) Comparison of background signal of different mouse strains imaged under the same scanning conditions: C57B6/l (black fur, left), mixed (B6/129S7, middle), and FVB/N (white fur, right). C) Visualization of anesthetized B6 mouse positioned for imaging. D) and in the intensity range between 3 (upper panel) and 4.5 (bottom panel) for the 700-channel with a z-offset of $0.0 \mathrm{~mm}$. 


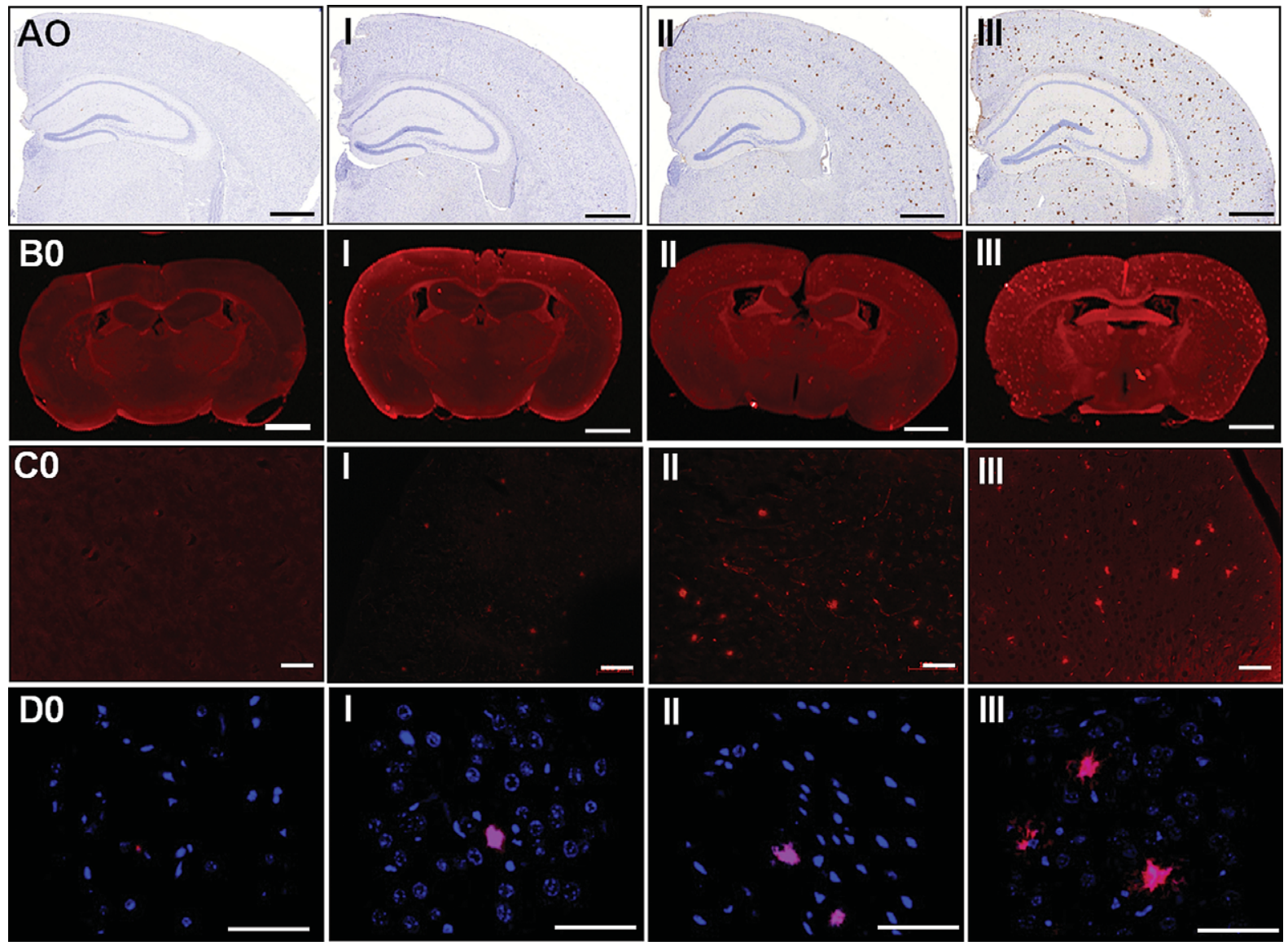

Fig. 2. Immunohistochemical stains of amyloid plaques in A $\beta P P$-transgenic mice at different disease stages. A) With increasing age, mice revealed a greater number of $\mathrm{A} \beta$-positive plaques. $4 \mu \mathrm{m}$-thick sections from paraffin-embedded brains were labeled with $6 \mathrm{~F} / 3 \mathrm{D}$ antibody. Slices were scanned with a Mirax slide scanner and analyzed at $50 \mathrm{~d}$ (0), $75 \mathrm{~d}$ (I), $100 \mathrm{~d}$ (II), and >200 d (III). Scale bars represent $500 \mu \mathrm{m}$. B, C) THK-265 staining of adjacent sections for $10 \mathrm{~min}$ at the same time points. Cryo-slices of $4 \mu \mathrm{m}$ thickness were imaged by OIIS (B) and at higher magnification $(20 \times)$ by fluorescence microscopy (C). D) Plaque number, size and area occupied by plaques increased continuously during the investigated period of time (50 to 200 days) and were obtained by LSM. Scale bar $50 \mu \mathrm{m}$.

(Fig. 2B). Additionally, higher magnification revealed enhanced amyloid plaque staining using fluorescence microscopy at different disease stages (Fig. 2C). Using a LSM we confirmed selective and efficient staining of $\mathrm{A} \beta$ plaques (red) in the transgenic mice (nuclear DAPI counterstain in blue; Fig. 2D).

\section{Ex vivo imaging of $A \beta$ deposits and establishment of imaging conditions for THK-265}

Additionally, the effects of plaque staining and THK-265 brain uptake were further characterized after distinct incubation times. Following intravenous administration into A $\beta P P$-transgenic mice (75 d), brains were removed after 10, 20, 30, 60, $90 \mathrm{~min}$, and $8 \mathrm{~h}$, and cryo-protected. We compared the NIRF sig- nals and found an increased IF signal in brains after 10,20 , and $90 \mathrm{~min}$, which decreased over time up to $8 \mathrm{~h}$ (Fig. 3AI-IV).

Next, we injected several concentrations $(0.01,1.0$, and $10 \mathrm{mg} / \mathrm{kg}$ ) of THK-265 dissolved in $10 \%$ DMSO and diluted in $0.1 \mathrm{MPBS}$ supplemented with $0.02 \mathrm{~mol} / \mathrm{l}$ $\mathrm{HCl}$. The best plaque labeling was achieved using $1 \mathrm{mg} / \mathrm{kg}$, which did not generate detectable toxicity effects in the brain, as shown in Fig. 3B. To demonstrate the cerebral distribution of THK-265 after i.v. application, $100 \mathrm{~d}$-old mice were killed without transcardial perfusion. During the first minutes after application, THK-265 was transported over the BBB into the brain. Usually, the fluorescence signal was stronger in A $\beta P P$ transgenic mice (Fig. 3CI), in contrast to age-matched controls (Fig. 3CII). 

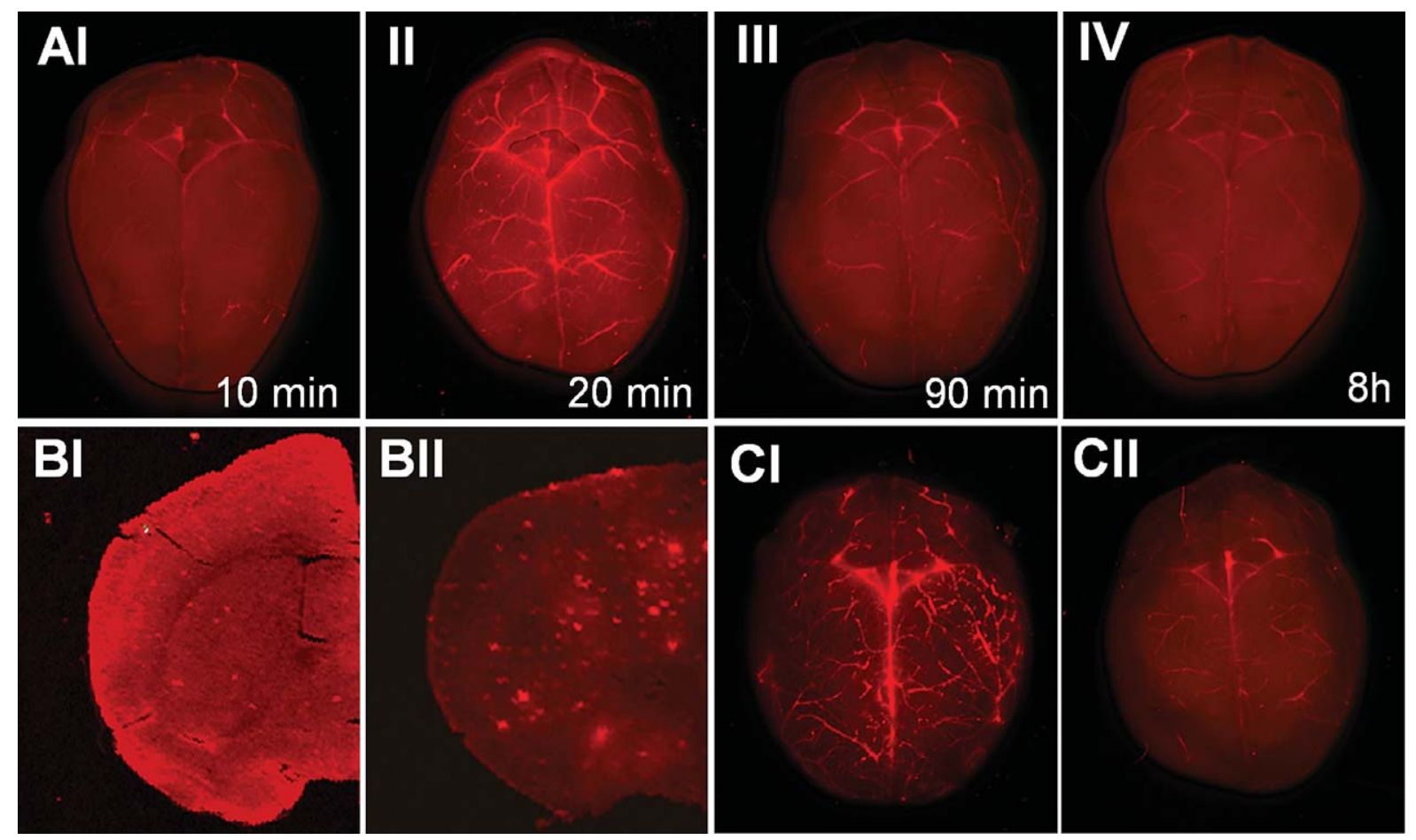

Fig. 3. Ex vivo labeling of A $\beta$ deposits in mouse brains and cryo-slices. A) Between 10 and 20 min after i.v. administration of THK-265, the near-infrared signal increased significantly and then decreased to a low signal after $8 \mathrm{~h}$. B) Differences in plaque labeling are shown in cryo-slices using two different concentrations of THK-265:0.01 mg (BI) and $1 \mathrm{mg}$ per kg mouse body weight (BII). THK-265 distribution in brains of 100 d old mice $(n>2)$ : after 30 min mice were killed and brains were removed. A $\beta$ PP-transgenic mice $(\mathrm{CI})$ showed higher signals than controls (CII).

In vivo imaging and quantification of $A \beta$ deposits in mouse brains

For in vivo imaging and quantification of $A \beta$ at different disease stages, THK-265 was used as a ligand to aggregated $A \beta$ and measured intracerebrally with an OIIS (LI-COR Biosciences). After intravenous administration of THK-265 (1 mg/kg body weight), mice were scanned at 10,20,30,60, and 90 min using the imaging parameters described above.

First, for visualization in the prone position and mapping of fluorescence signal in the head region, photos of the anesthetized mice were taken. The head, body, and tail of a living mouse positioned for imaging are illustrated in Fig. 4A0. Next, we compared the overall cerebral uptake of THK-265 at different ages of each mouse modeling the progression of cerebral $\mathrm{A} \beta$ deposition: $75 \mathrm{~d}$ (Fig. 4AI), $100 \mathrm{~d}$ (Fig. 4BI), and older than $200 \mathrm{~d}$ (Fig. 4CI), and compared the results with age-matched, nontransgenic control mice ( $n \geq 5$, Fig. 4AII-CII). We observed an increase of the NIRF signal in the
AßPP-transgenic mice correlating with age, whereas the signal in the age-matched, non-transgenic controls did not vary versus baseline. Male (upper row) and female mice (bottom row) did not show significant differences.

For quantification of signal intensity, the region of interest in the mouse head was analyzed and quantified against the background signal in the trunk of the mice. For this reason, a representative image of the 75 d-old mouse is shown in Fig. 5A0 and the same regions of interest were selected for all mice. The $A \beta$ load was quantified by comparing the NIRF signal intensities at $30 \mathrm{~min}$ in the A $\beta P P$-transgene-positive group ( $n \geq 5)$ and normalized against the measurement background: $75 \mathrm{~d}$ of age (Fig. 5A); $100 \mathrm{~d}$ (Fig. 5B); $>200 \mathrm{~d}$ (Fig. 5C) with A $\beta P P$ transgene $\left(\mathrm{A} \beta \mathrm{PP}^{+/ 0}, \mathrm{I}\right)$, or without $\left(\mathrm{A} \beta \mathrm{PP}^{0 / 0}, \mathrm{II}\right)$. Thus, THK-265 can be used to determine that, with increased age, the $A \beta$ deposits and therefore the fluorescence signal increases significantly (Fig. 5D, grey columns, $p \geq 0.05$ ). Furthermore, the NIRF signal did not change in controls at any of the analyzed time points (black columns). 


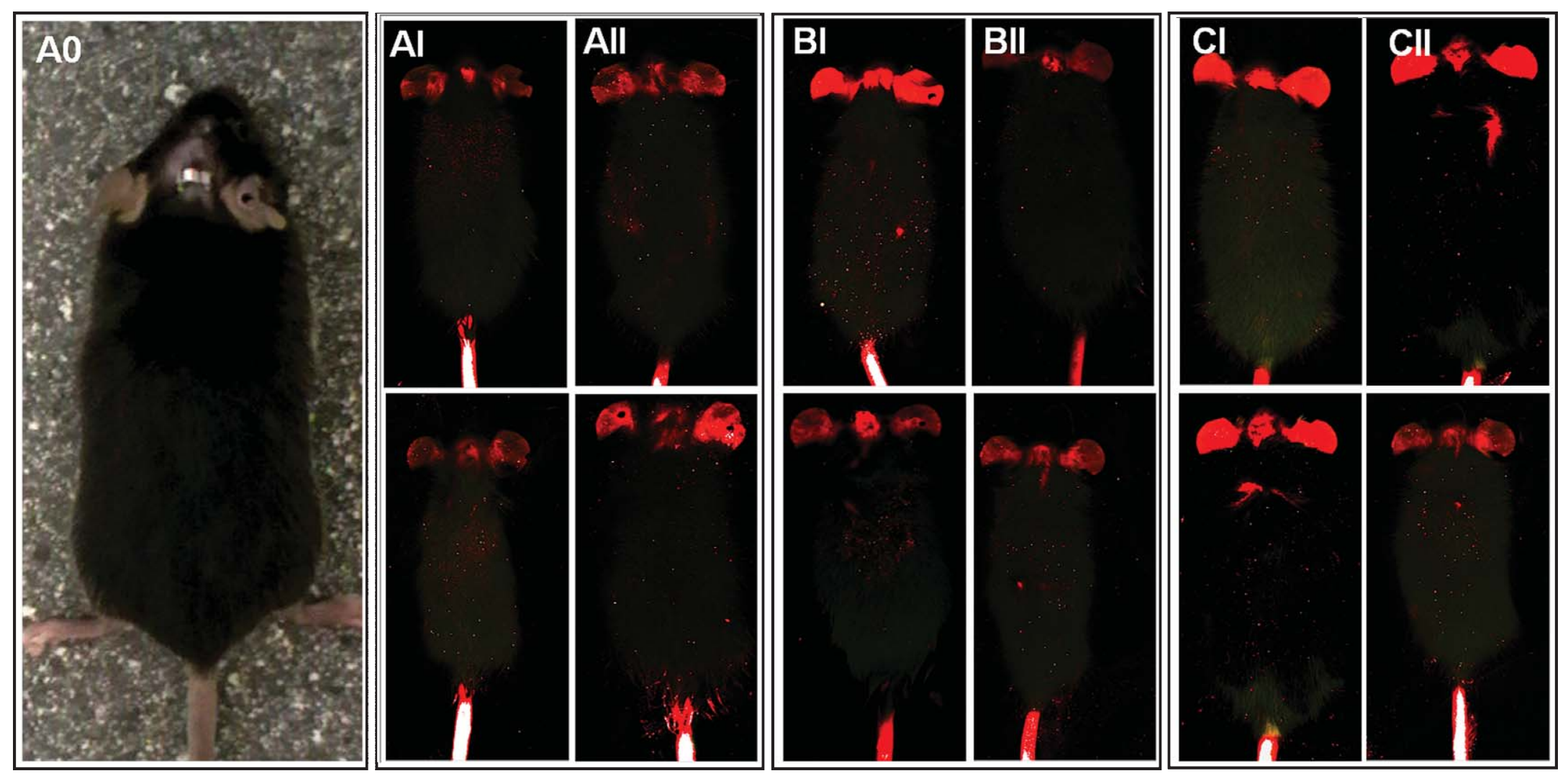

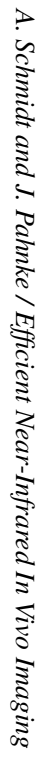

Fig. 4. In vivo administration of THK-265 into A $\beta$ PP-transgenic and control mice. A $\beta$ deposits in the brain were visualized by in vivo imaging with the OIIS system 30 min after THK-265

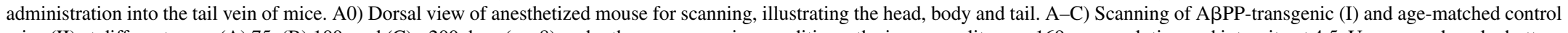
mice (II) at different ages: (A) 75, (B) 100, and (C) >200 days $(n>8)$ under the same scanning conditions: the image quality was $169 \mu \mathrm{m}$ resolution and intensity at 4.5. Upper panel, male; bottom panel, female mice. 

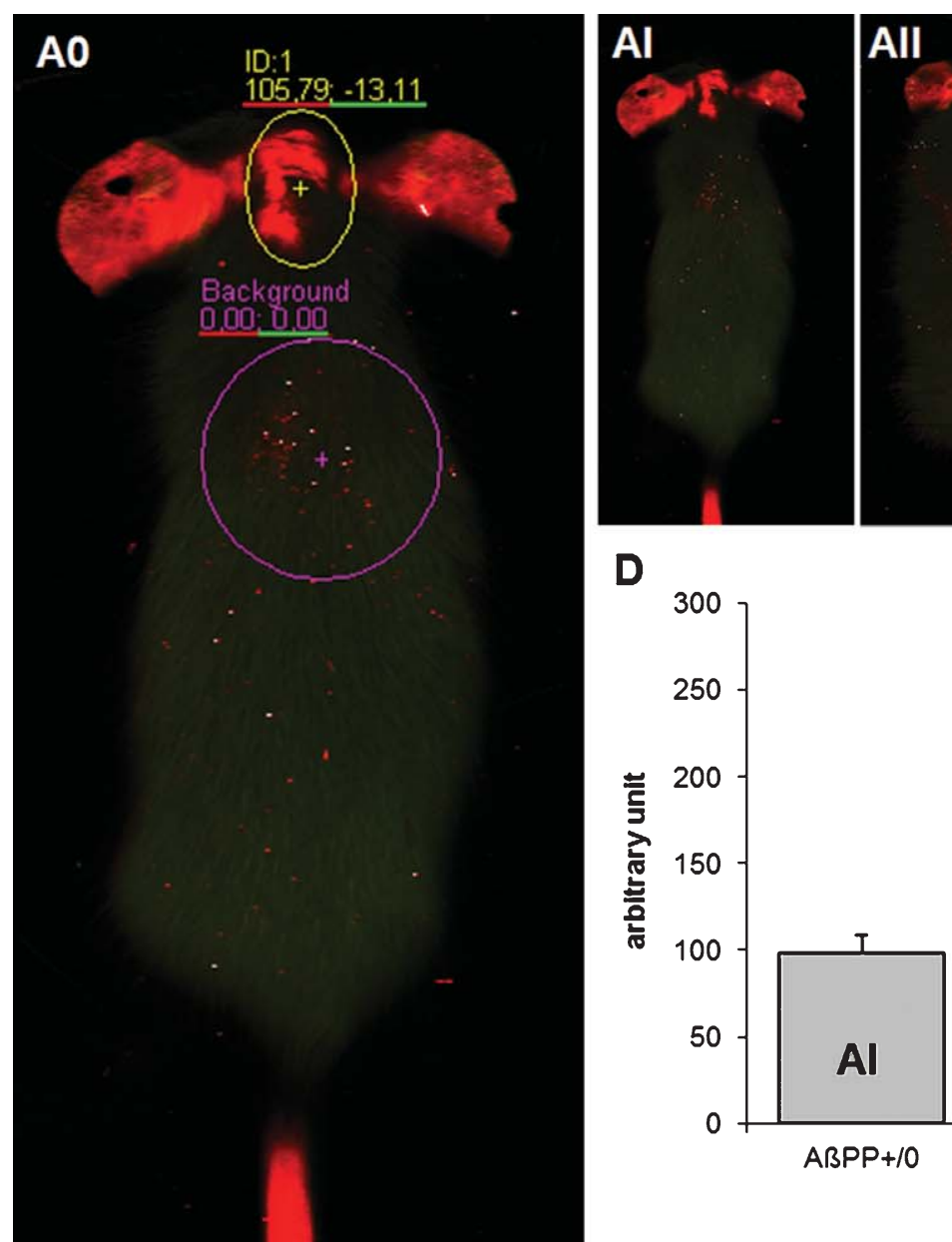

Bl

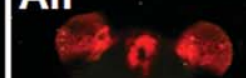

\section{BI}

40

BII

III
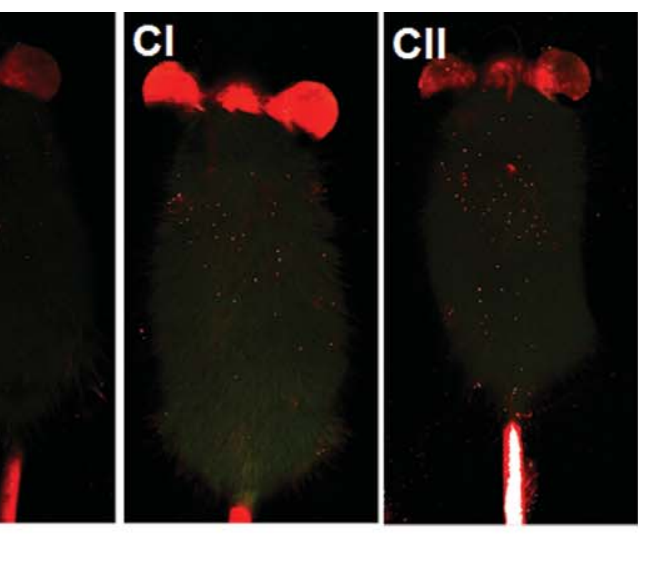

D

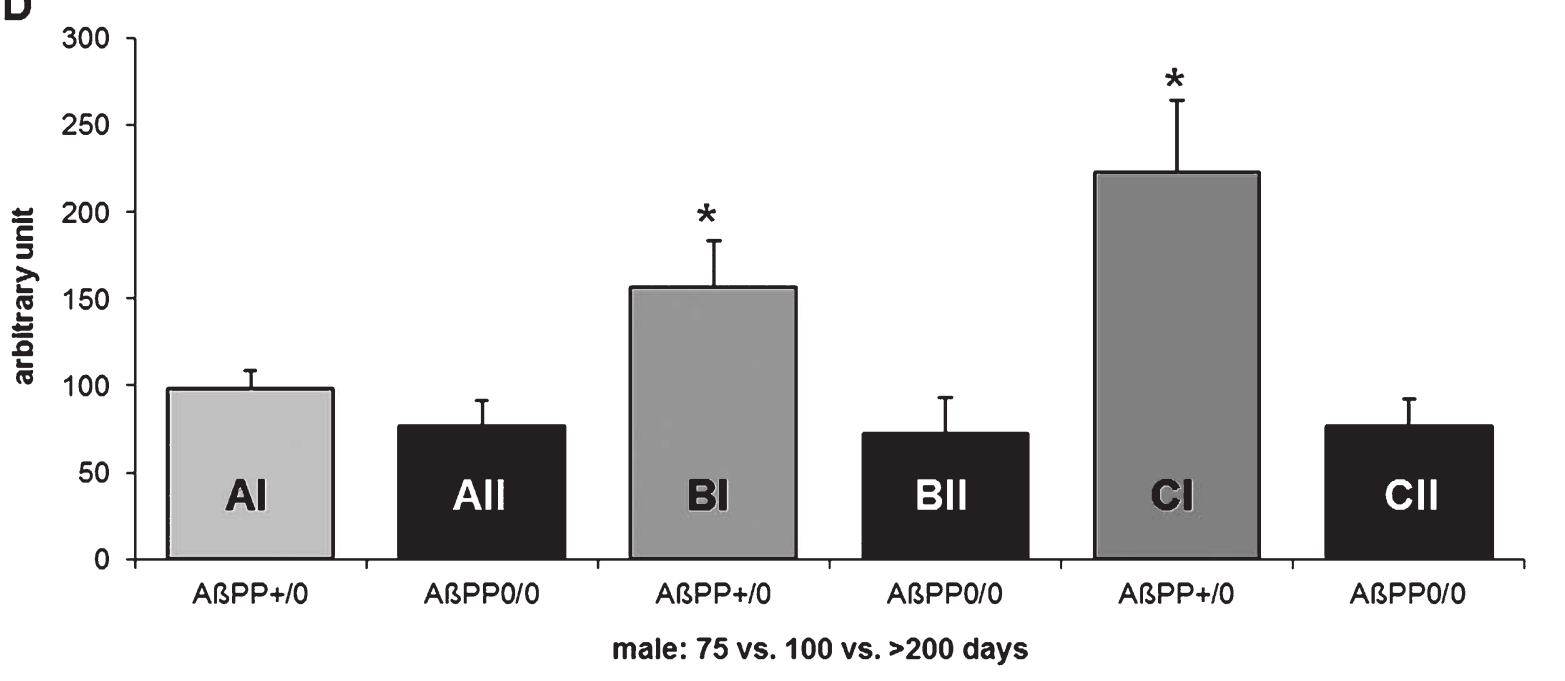

Fig. 5. Quantification of signal intensity. For infrared signal quantification, the THK-265 signal was analyzed as the average 700-channel integrated intensities from $n>5$ mice (dorsal position as in Fig. 4A0) normalized to the background (A0). Results are expressed as arbitrary units (means \pm standard errors of the mean) compared to treated age-matched controls. A-C) Imaged scans of males were semi-quantitatively measured by comparing the fluorescence signal intensity normalized against background signal $(75 \mathrm{~d} \mathrm{~A} ; 100 \mathrm{~d} \mathrm{~B} ;>200 \mathrm{~d}$ C). D) The diagram (AU - arbitrary units) shows a significant enhancement of signal intensities with increasing age (75-200 d), (I - A $\beta P P$-transgene positive, A $\beta P^{+/ 0}$ ), whereas controls revealed no changes in signal intensity (II - $\left.\mathrm{A} \beta \mathrm{PP}^{0 / 0}\right) ; * p<0.05$. 

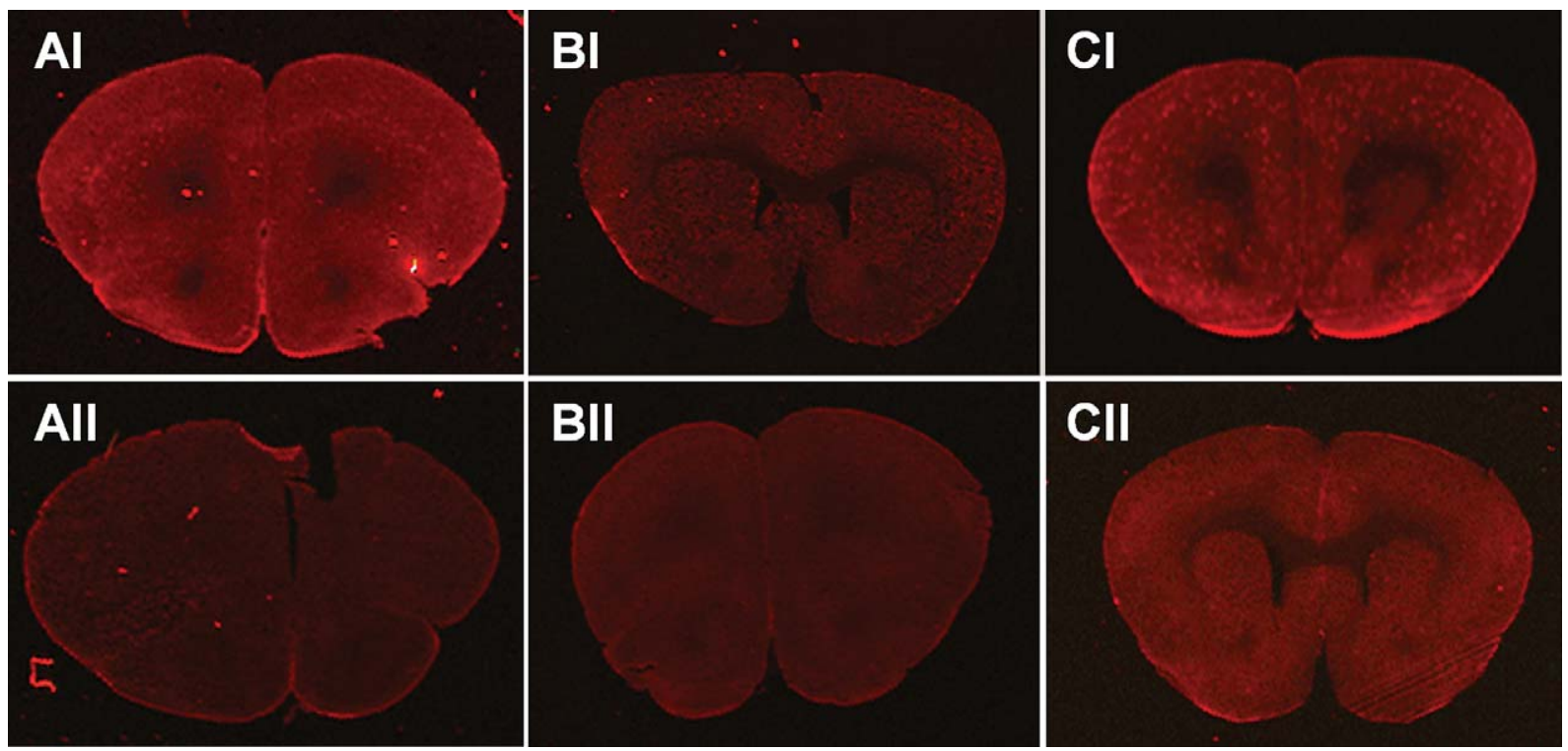

Fig. 6. Ex vivo labeling of $\mathrm{A} \beta$ deposits in brain cryo-slices. A) Ex vivo visualization of THK-265-infrared signal in cryo-sections at $75 \mathrm{~d}$ (C), $100 \mathrm{~d}(\mathrm{D})$ and $>200 \mathrm{~d}$ (E) older A $\beta$ PP-transgenic (I) and age-matched control mice (II).

\section{Ex vivo plaque staining after i.v. THK-265 administration}

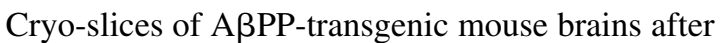
i.v. injection of THK-265 showed an increase of the near-infrared signal in relation to plaque amount and concentration of NIRF dye. Representative images of each group are shown in Fig. 6AI-CI. In older mice more labeled plaques were detected, confirming the in vivo results, whereas no signal could be observed in non-transgenic, age-matched controls (Fig. 6AIICII).

The staining of amyloid deposits with THK265 in whole brain slices was monitored by an automated brightfield and fluorescence MiraxMidi scanner (Zeiss MicroImaging GmbH). For a 200 dold A $\beta$ PP-transgenic mouse, different magnifications were imaged to demonstrate excellent THK-labeling of $\mathrm{A} \beta$ plaques in the forebrain (Fig. 7AI-V). Assessment of $\mathrm{A} \beta$ targeting characteristics was performed in all groups and mapped with disease progression [(I) $75 \mathrm{~d}$; (II) $100 \mathrm{~d}$; (III) $>200 \mathrm{~d}$ mice] and distinct regions were analyzed at different magnifications using a LSM (Fig. 7B). Ex vivo staining of plaques with THK-265 confirmed the possibility of a direct real-time monitoring in living animals. Again, with increasing plaque number the fluorescence signal of THK-265 was significantly stronger. Additionally, brain slices were stained fluorescently with specific $A \beta$ antibody (clone 6E10) to visualize plaques (Fig. 7C). Furthermore, fluorescent co-staining of amyloid deposits with both THK-265 (green) and 6E10 (red) was monitored by LSM in all groups (nuclear DAPI counterstain in blue, Fig. 7D).

\section{DISCUSSION}

The successful development of a non-invasive optical measurement platform for $\mathrm{A} \beta$ would enable inexpensive, accessible, and non-radioactive detection of early $\mathrm{A} \beta$ deposits for the diagnosis of $\mathrm{AD}$ and the surveillance of anti-A $\beta$ treatment. Such a technical approach could be an efficient strategy for in vivo $\mathrm{A} \beta$ plaque imaging in patients, and could also be used as a useful tool for biomarker candidate identification. Furthermore, pre-symptomatic, early, and non-invasive diagnosis of $\mathrm{AD}$ and other neurodegenerative diseases is crucial for effective therapeutic interventions [1]. One major characteristic of $\mathrm{AD}$ is the continuously increasing protein deposition over many years. In this regard, the development of low-molecular weight compounds for direct imaging of these protein deposits in neurodegenerative diseases is currently an emerging field of research. Several requirements should be noted: First, the intrinsic fluorescence of imaging fluorophores presents a problem when they emit visible light in a range between $350-700 \mathrm{~nm}$. Whereas infrared 

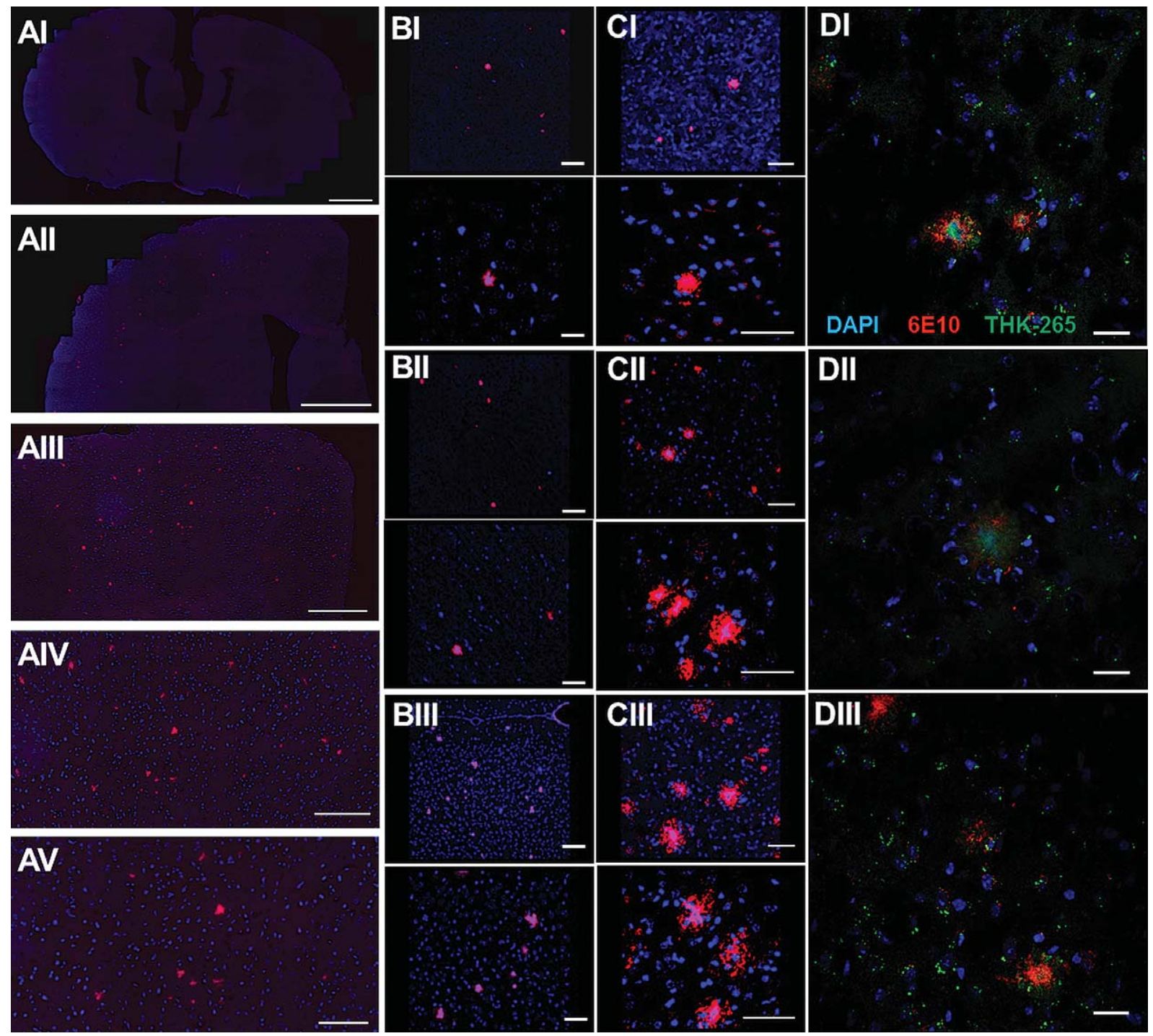

Fig. 7. Double labeling of $A \beta$ plaques after i.v. administration of THK-265. A) Fluorescent staining of plaques ( $16 \mu$ m-thick slices) after i.v. administration of THK-265 into A $\beta$ PP-transgenic mouse brains using the Mirax scanner at different magnifications. Scale bar $1000 \mu \mathrm{m}$ (I) $500 \mu \mathrm{m}$ (II), $200 \mu \mathrm{m}$ (III), $100 \mu \mathrm{m}$ (IV), and $50 \mu \mathrm{m}$ (V). Plaques were stained with THK-265 (B) or an Aß-specific antibody (clone 6E10) (C) and visualized using laser scanning microscopy (LSM700) at different magnifications. Scale bar 100 and $50 \mu \mathrm{m}$, respectively. D) Double-labeling of fluorescently stained plaques with THK-265 (green) and 6E10 antibody (red). DAPI was employed for nuclear counterstaining (blue). Scale bar $50 \mu \mathrm{m}$.

biomolecules have suitable excitation and emission wavelengths between $600-800 \mathrm{~nm}$, they also require spatial integration with amyloid. Novel near-infrared fluorescence (NIRF) probes with appropriate lipophilic properties and blood-brain barrier permeability are excellent alternatives for the visualization of protein deposits [21, 22, 27]. Second, natural background fluorescence interference is a potential problem, but this is minimized by NIRF probes, which yield high con- trast between target and background tissues [33]. Last but not least, NIRF probes are cheap and useful alternatives to radio-labeled, short-lived isotopes for positron and single-photon emission computerized tomography (PET/SPECT). Non-invasive techniques, such as molecular imaging with PET, might overcome some of the limitations of bioluminescence detection, but require the availability of complex hardware and high expenditure of time [34]. 
Recently, it was shown that the NIRF dye THK-265 specifically detects amyloid deposits with high binding affinity to amyloid fibrils in an A $\beta P P$-transgenic mouse model [27]. In contrast to the A $\beta P P$-transgenic mice used by Okamura, which produce the first $A \beta$ deposits relatively late, we developed a specific procedure for non-invasive in vivo and ex vivo imaging of $\mathrm{A} \beta$ deposits using THK-265 that allows us to assess differences in $A \beta$ levels in an A $\beta P P$-transgene mouse model at early points in time (75 days) and different pathologyrelated stages of amyloidosis. The transgenic mouse system enables imaging in a controlled and consistent microenvironment and is well characterized at different stages of $A \beta$ accumulation [29, 31, 32].

In a longitudinal study, amyloid plaques were analyzed in vitro and compared with different points in time or with non-transgenic controls at an age of 75, 100 , to 200 days. To confirm our findings that the signal intensity is tightly correlated to the differences in plaque load, reflecting the activity and aggregation state of $A \beta$, we also performed direct measurements of infrared fluorescence signal in living male and female mice (Fig. 4). Our in vivo findings support the feasibility of using THK-265 to visualize the increase in $A \beta$ deposits with increasing age by detecting increased NIRF signal intensities (Fig. 5). However, one critical point should be noted: in all non-transgenic control mice $\left(\mathrm{A} \beta \mathrm{PP}^{0 / 0}\right)$ an infrared signal was also observed by in vivo imaging with OIIS which was evoked from early THK-265 transport from the blood vessels into the brain during the first minutes after i.v. application. As a consequence, the infrared signal from the vessels appears to dominate over the plaque staining at very early time points between 50 and 75 days in AßPP-transgenic mice. Quantification of the fluorescence signal resulted in slight differences in the $75 \mathrm{~d}$-old AßPP-transgene positive group (AI) in contrast to control mice (AII, in Fig. 5D).

Recent publications by other groups have reported on the biodistribution of NIRF probes, providing important information on brain uptake and penetration to deliver sufficient amounts of NIRF probes across the BBB as well as their elimination from brain [18, $19,22,27]$. Here, we confirmed significant penetration of THK-265 into the brain and its rapid uptake within 10 min after i.v. administration (Fig. 3A), underscoring favorable properties of this NIRF dye to assess $\mathrm{A} \beta$ deposits.

We also confirmed a decrease in signal intensity in the vessels by elimination of THK-265 from the blood stream approximately $90 \mathrm{~min}$ up to eight hours after i.v. administration (Fig. 3A), suggesting predom- inantly binding of the dye to $A \beta$ plaques in the cortex regions. Furthermore, the $A \beta$ deposition was highly increased in much older mice ( $>200 \mathrm{~d}$ ); where extensive $A \beta$ deposition coincides with strong NIRF signal intensity in brains in vivo (Figs. $4 \mathrm{C}$ and $5 \mathrm{C}$ ).

Immunofluorescence images obtained by several microscopic methods after i.v. application of THK265 (Figs. 6 and 7), and immunohistochemical ex vivo labeling of $A \beta$ plaques using the NIRF dye and $A \beta$ specific antibodies (Fig. 2) confirmed that the changes in the infrared signal intensity were mediated by differences in the $A \beta$ load.

Our results demonstrate that changes in NIRF signal intensity are only weakly correlated with changes in $A \beta$ burden at very early stages of cerebral amyloidosis (Figs. 4A and 5A), suggesting the need for higher sensitivity including lower detection levels. These objectives can be achieved by the enhancement of the NIRF probes with respect to the emission signal. In this context, we should mention the higher signal intensity in humans due to the size of the human brain and a more restricted signal monitoring option to the region of interest, e.g., temporal lobe. Furthermore, distribution differences in the fluorescence signal can be overcome by normalizing the measured fluorescence intensity with a reference background in patients or cortical areas bearing no amyloid plaques.

Another positive feature of NIRF probe THK-265 is the lack of obvious toxicity after i.v. administration at the described concentrations (also reported by [27]), indicating a beneficial use of related dyes for application in patients. Thus, many methodological limitations associated with contrast agents might be obviated by the use of NIRF probes, including toxicity at higher concentrations, the route of administration, hydrophobicity and associated risks such as longer brain retention [21].

With respect to current PET studies with biomarkers of regional neuronal activity and amyloidosis, $A \beta$ deposits provide complementary information for the early diagnosis and follow-up of patients with dementia $[35,36]$. In this context, it should be mentioned that the resolution and quantitative ability of in vivo NIRF imaging in patients currently would be as low as PET using radionuclide tracers. However, PET scanning still has several disadvantages, including low availability, low resolution to identify individual plaques as well as the requirement for radioactive substances [34, 37]. Additionally, PET is an expensive technique that it is not widely available for preclinical, small animal studies in basic research that serve as a basis for future human trials. 


\section{CONCLUSIONS}

In summary, we developed and tested a procedure that allowed us to visualize cerebral amyloid deposits for the non-invasive detection and real-time monitoring of $\mathrm{A} \beta$ accumulation at different stages of the process. NIRF dyes may serve as new diagnostic tools for humans with neurodegenerative disorders in which protein deposits, e.g., A $\beta$ aggregates, arise over many years. Specifically, our approach indicates that the NIRF dye THK-265 is an excellent starting point for developing this approach for use in human diagnostics. Furthermore, THK-265 or similar NIRF probes may facilitate the evaluation of new therapeutic strategies for $\mathrm{AD}$.

\section{ACKNOWLEDGMENTS}

The authors especially thank Anne-Sophie Plath and Thomas Brüning for their helpful support with histology, Gerda Brüsch and the whole NRL team Rostock for animal housing, and Lary C. Walker for helpful comments on the manuscript.

A.S. was funded by the DZNE Rostock. The equipment and chemicals for the experiments were funded by the NRL Rostock. J.P. was/is funded by the DZNE Rostock and Magdeburg and the Universities Rostock and Magdeburg/Departments of Neurology.

Authors' disclosures available online (http://www.jalz.com/disclosures/view.php?id=1198).

\section{REFERENCES}

[1] Sperling RA, Jack CR Jr, Aisen PS (2011) Testing the right target and right drug at the right stage. Sci Transl Med 3, 111-133.

[2] Giacobini E, Becker RE (2007) One hundred years after the discovery of Alzheimer's disease. A turning point for therapy? $J$ Alzheimers Dis 12, 37-52.

[3] Giacobini E (2004) Cholinesterase inhibitors: New roles and therapeutic alternatives. Pharmacol Res 50, 433-440.

[4] Lewczuk P, Kornhuber J, Vanderstichele H, Vanmechelen E, Esselmann H, Bibl M, Wolf S, Otto M, Reulbach U, Kolsch H, Jessen F, Schroder J, Schonknecht P, Hampel H, Peters O, Weimer E, Perneczky R, Jahn H, Luckhaus C, Lamla U, Supprian T, Maler JM, Wiltfang J (2008) Multiplexed quantification of dementia biomarkers in the CSF of patients with early dementias and MCI: A multicenter study. Neurobiol Aging 29, 812-818.

[5] Brys M, Pirraglia E, Rich K, Rolstad S, Mosconi L, Switalski R, Glodzik-Sobanska L, De Santi S, Zinkowski R, Mehta P, Pratico D, Saint Louis LA, Wallin A, Blennow K, de Leon MJ (2009) Prediction and longitudinal study of CSF biomarkers in mild cognitive impairment. Neurobiol Aging 30, 682-690.

[6] Gabelle A, Roche S, Geny C, Bennys K, Labauge P, Tholance Y, Quadrio I, Tiers L, Gor B, Chaulet C, Vighetto A, Croisile
B, Krolak-Salmon P, Touchon J, Perret-Liaudet A, Lehmann S (2010) Correlations between soluble alpha/beta forms of amyloid precursor protein and Abeta38, 40, and 42 in human cerebrospinal fluid. Brain Res 1357, 175-183.

[7] Lue LF, Kuo YM, Roher AE, Brachova L, Shen Y, Sue L, Beach T, Kurth JH, Rydel RE, Rogers J (1999) Soluble amyloid beta peptide concentration as a predictor of synaptic change in Alzheimer's disease. Am J Pathol 155, 853-862.

[8] Lesné S, Koh MT, Kotilinek L, Kayed R, Glabe CG, Yang A, Gallagher M, Ashe KH (2006) A specific amyloid-beta protein assembly in the brain impairs memory. Nature 440, 352-357.

[9] Tsai J, Grutzendler J, Duff K, Gan WB (2004) Fibrillar amyloid deposition leads to local synaptic abnormalities and breakage of neuronal branches. Nat Neurosci 7, 11811183.

[10] Walsh DM, Klyubin I, Fadeeva JV, Cullen WK, Anwyl R, Wolfe MS, Rowan MJ, Selkoe DJ (2002) Naturally secreted oligomers of amyloid beta protein potently inhibit hippocampal long-term potentiation in vivo. Nature 416, 535-539.

[11] Wang HW, Pasternak JF, Kuo H, Ristic H, Lambert MP, Chromy B, Viola KL, Klein WL, Stine WB, Krafft GA, Trommer BL (2002) Soluble oligomers of beta amyloid (1-42) inhibit long-term potentiation but not long-term depression in rat dentate gyrus. Brain Res 924, 133-140.

[12] Westerman MA, Cooper-Blacketer D, Mariash A, Kotilinek L, Kawarabayashi T, Younkin LH, Carlson GA, Younkin SG, Ashe KH (2002) The relationship between Abeta and memory in the $\mathrm{Tg} 2576$ mouse model of Alzheimer's disease. $J$ Neurosci 22, 1858-1867.

[13] Cummings BJ, Pike CJ, Shankle R, Cotman CW (1996) Betaamyloid deposition and other measures of neuropathology predict cognitive status in Alzheimer's disease. Neurobiol Aging 17, 921-933.

[14] Aslund A, Sigurdson CJ, Klingstedt T, Grathwohl S, Bolmont T, Dickstein DL, Glimsdal E, Prokop S, Lindgren M, Konradsson P, Holtzman DM, Hof PR, Heppner FL, Gandy S, Jucker M, Aguzzi A, Hammarstrom P, Nilsson KP (2009) Novel pentameric thiophene derivatives for in vitro and in vivo optical imaging of a plethora of protein aggregates in cerebral amyloidoses. ACS Chem Biol 4, 673-684.

[15] Niikura T, Tajima H, Kita Y (2006) Neuronal cell death in Alzheimer's disease and a neuroprotective factor, humanin. Curr Neuropharmacol 4, 139-147.

[16] Frangioni JV (2003) In vivo near-infrared fluorescence imaging. Curr Opin Chem Biol 7, 626-634.

[17] Wollmer MA, Streffer JR, Lutjohann D, Tsolaki M, Iakovidou V, Hegi T, Pasch T, Jung HH, Bergmann K, Nitsch RM, Hock C, Papassotiropoulos A (2003) ABCA1 modulates CSF cholesterol levels and influences the age at onset of Alzheimer's disease. Neurobiol Aging 24, 421-426.

[18] Bertoncini CW, Celej MS (2011) Small molecule fluorescent probes for the detection of amyloid self-assembly in vitro and in vivo. Curr Protein Pept Sci 12, 205-220.

[19] Nesterov EE, Skoch J, Hyman BT, Klunk WE, Bacskai BJ, Swager TM (2005) In vivo optical imaging of amyloid aggregates in brain: Design of fluorescent markers. Angew Chem Int Ed Engl 44, 5452-5456.

[20] Nilsson KP, Hammarstrom P, Ahlgren F, Herland A, Schnell EA, Lindgren M, Westermark GT, Inganas O (2006) Conjugated polyelectrolytes-conformation-sensitive optical probes for staining and characterization of amyloid deposits. Chembiochem 7, 1096-1104.

[21] Raymond SB, Kumar AT, Boas DA, Bacskai BJ (2009) Optimal parameters for near infrared fluorescence imaging of 
amyloid plaques in Alzheimer's disease mouse models. Phys Med Biol 54, 6201-6216.

[22] Hintersteiner M, Enz A, Frey P, Jaton AL, Kinzy W, Kneuer R, Neumann U, Rudin M, Staufenbiel M, Stoeckli M, Wiederhold KH, Gremlich HU (2005) In vivo detection of amyloid-beta deposits by near-infrared imaging using an oxazine-derivative probe. Nat Biotechnol 23, 577-583.

[23] Ran C, Xu X, Raymond SB, Ferrara BJ, Neal K, Bacskai BJ, Medarova Z, Moore A (2009) Design, synthesis, and testing of difluoroboron-derivatized curcumins as near-infrared probes for in vivo detection of amyloid-beta deposits. J Am Chem Soc 131, 15257-15261.

[24] Fodero-Tavoletti MT, Okamura N, Furumoto S, Mulligan RS, Connor AR, McLean CA, Cao D, Rigopoulos A, Cartwright GA, O'Keefe G, Gong S, Adlard PA, Barnham KJ, Rowe CC, Masters CL, Kudo Y, Cappai R, Yanai K, Villemagne VL (2011) 18F-THK523: A novel in vivo tau imaging ligand for Alzheimer's disease. Brain 134, 1089-1100.

[25] Ojida A, Sakamoto T, Inoue MA, Fujishima SH, Lippens G, Hamachi I (2009) Fluorescent BODIPY-based Zn(II) complex as a molecular probe for selective detection of neurofibrillary tangles in the brains of Alzheimer's disease patients. $J$ Am Chem Soc 131, 6543-6548.

[26] Luna-Munoz J, Peralta-Ramirez J, Chavez-Macias L, Harrington CR, Wischik CM, Mena R (2008) Thiazin red as a neuropathological tool for the rapid diagnosis of Alzheimer's disease in tissue imprints. Acta Neuropathol 116, 507-515.

[27] Okamura N, Mori M, Furumoto S, Yoshikawa T, Harada R, Ito S, Fujikawa Y, Arai H, Yanai K, Kudo Y (2011) In vivo detection of amyloid plaques in the mouse brain using the near-infrared fluorescence probe THK-265. J Alzheimers Dis 23, 37-48.

[28] Radde R, Bolmont T, Kaeser SA, Coomaraswamy J, Lindau D, Stoltze L, Calhoun ME, Jaggi F, Wolburg H, Gengler S, Haass C, Ghetti B, Czech C, Holscher C, Mathews PM, Jucker M (2006) Abeta42-driven cerebral amyloidosis in transgenic mice reveals early and robust pathology. EMBO Rep 7, 940946.

[29] Scheffler K, Stenzel J, Krohn M, Lange C, Hofrichter J, Schumacher T, Bruning T, Plath AS, Walker L, Pahnke J (2011) Determination of spatial and temporal distribution of microglia by $230 \mathrm{~nm}$-high-resolution, high-throughput automated analysis reveals different amyloid plaque populations in an A $\beta P P / P S 1$ mouse model of Alzheimer's disease. Curr Alzheimer Res 8, 781-788.

[30] Teipel SJ, Buchert R, Thome J, Hampel H, Pahnke J (2011) Development of Alzheimer-disease neuroimagingbiomarkers using mouse models with amyloid-precursor protein-transgene expression. Prog Neurobiol 95, 547-556.

[31] Teipel SJ, Kaza E, Hadlich S, Bauer A, Bruning T, Plath AS, Krohn M, Scheffler K, Walker LC, Lotze M, Pahnke J (2011) Automated detection of amyloid-beta-related cortical and subcortical signal changes in a transgenic model of Alzheimer's disease using high-field MRI. $J$ Alzheimers Dis 23, 221-237.

[32] Krohn M, Lange C, Hofrichter J, Scheffler K, Stenzel J, Steffen J, Schumacher T, Bruning T, Plath AS, Alfen F, Schmidt A, Winter F, Rateitschak K, Wree A, Gsponer J, Walker LC, Pahnke J (2011) Cerebral amyloid-beta proteostasis is regulated by the membrane transport protein $\mathrm{ABCC} 1$ in mice. J Clin Invest 121, 3924-3931.

[33] Leung K (2004) 2-[2-[2-Chloro-3-[2-[1,3-dihydro-3,3dimethyl-1-(4-sulfobutyl)-2H-indol-2-ylidene]-ethylidene]1-cyclohexen-1-yl]-ethenyl]-3,3-dimethyl-1-(4-sulfobutyl)3H-indolium. In: Molecular Imaging and Contrast Agent Database (MICAD) [database online]. National Library of Medicine (US), NCBI, Bethesda (MD); 2004-2012. Available from: http://micad.nih.gov.

[34] Skoch J, Dunn A, Hyman BT, Bacskai BJ (2005) Development of an optical approach for noninvasive imaging of Alzheimer's disease pathology. J Biomed Opt 10, 11007.

[35] Koivunen J, Scheinin N, Virta JR, Aalto S, Vahlberg T, Nagren K, Helin S, Parkkola R, Viitanen M, Rinne JO (2011) Amyloid PET imaging in patients with mild cognitive impairment: A 2-year follow-up study. Neurology 76, 1085-1090.

[36] Meyer PT, Hellwig S, Amtage F, Rottenburger C, Sahm U, Reuland P, Weber WA, Hull M (2011) Dual-biomarker imaging of regional cerebral amyloid load and neuronal activity in dementia with PET and 11C-labeled Pittsburgh compound B. J Nucl Med 52, 393-400.

[37] Chamberlain R, Reyes D, Curran GL, Marjanska M, Wengenack TM, Poduslo JF, Garwood M, Jack CR Jr (2009) Comparison of amyloid plaque contrast generated by $\mathrm{T} 2$-weighted, $\mathrm{T} 2 *$-weighted, and susceptibility-weighted imaging methods in transgenic mouse models of Alzheimer's disease. Magn Reson Med 61, 1158-1164. 